\title{
Synthesis and Thermal Behavior of Metallic Cobalt Micro and Nanostructures
}

\author{
Marlene González Montiel ${ }^{1}$, P. Santiago-Jacinto ${ }^{2}$, J. A. I. Díaz Góngora ${ }^{1}$, E. Reguera ${ }^{1}$, Geonel \\ Rodríguez-Gattorno ${ }^{1,3, *}$
}

(Received 5 Jan 2011; accepted 9 Mar 2011; published online 7 April 2011.)

\begin{abstract}
In this contribution, a comparative study of metallic cobalt micro and nanoparticles obtained in solution by four different chemical routes is reported. Classic routes such as borohydride reduction in aqueous media and the so-called polyol methodology were used to obtain the cobalt nanostructures to be studied. Using CTAB as surfactant, cobalt hollow nanostructures were obtained. The use of strong reducing agents, like sodium borohydride, favors the formation of quasi-monodispersed nanoparticles of about $2 \mathrm{~nm}$ size but accompanied with impurities; for hydrazine (a mild reducer), nanoparticles of larger size are obtained which organize in spherical microagglomerates. Valuable information on the particles thermal stability and on nature of the species anchored at their surface was obtained from thermogravimetric curves. The samples to be studied were characterized from UV-vis, IR, X-ray diffraction, and electron microscopy images (scanning and transmission). Keywords: Metallic Cobalt; Cobalt nanoparticles; Magnetic nanoparticles; Hollow magnetic microparticles
\end{abstract}

Citation: Marlene González Montiel, P. Santiago-Jacinto, J. A. I. Díaz Góngora, E. Reguera and Geonel Rodríguez-Gattorno, "Synthesis and Thermal Behavior of Metallic Cobalt Micro and Nanostructures", NanoMicro Lett. 3 (1), 12-19 (2011). http://dx.doi.org/10.3786/nml.v3i1.p12-19

\section{Introduction}

The preparation of cobalt nanoparticles has been widely studied related to their promising applications in various areas, among them: recording media [1], magnetic sensors [2], magnetic memories [3], magnetic fluids [4], magnetic composites [5] and catalysis [6]. All these applications demand high purity grade products in order to avoid alteration in their magnetization or response stability [7]. Nowadays most of the nanostructured materials are obtained in phase solution, because it is simple, reliable and economic route allowing the tailoring of material properties through the control of mean particle sizes and particle sizes distribution. However, due to instability of nanostructured materials as result of its excess of surface energy, the use of capping agents has become a very common way to sta- bilize nanoparticles in solution phase. Hence, it is not surprising that products in nanoparticles synthesis are frequently and highly unpurified by capping agents and solvent molecules, and the exhaustive routines of purification do not necessarily resolve this problem.

In the later years several synthesis of metallic cobalt nanoparticles have been reported and most of them mention the nanoparticles oxidize in solution or in contact with air, however systematic studies on this topic is still absent. Therefore emerge the requirement to investigate quantitatively and qualitatively the oxidation phenomena in this type of particles in order to increase the efficiency of variety processes in different research areas, especially for nanostructured materials which practically are deficient in information related to the stabilization studies towards the oxidation processes. On the other hand, thermal analysis is a simple qualita-

\footnotetext{
${ }^{1}$ Centro de Investigación en Ciencia Aplicada y Tecnología Avanzada. Legaria 694, Col Irrigación, Miguel Hidalgo, CP 11500 Ciudad de México D.F., México

${ }^{2}$ Instituto de Física, Circuito de la Investigación Científica Ciudad Universitaria CP 04510 México, D.F., México

${ }^{3}$ Departamento de Física Aplicada, CINVESTAV-IPN, Mérida, Yucatán, 97310, México

*Corresponding author. E-mail:geonelr@mda.cinvestav.mx
} 
Nano-Micro Lett. 3 (1), 12-19 (2011)/http://dx.doi.org/10.3786/nml.v3i1.p12-19

tive and quantitative analytical tool allowing the study of decomposition and oxidation processes, specially the thermogravimetric analysis which allows characterizing the oxidation of many metals under accelerated conditions. Few works focused on the chemical quantification of unpurified products that results from the strong interactions at the interface: nanoparticle-media during synthesis procedures. Therefore, in the present work the oxidation thermal profiles of metallic cobalt nano and micro particles obtained in colloidal dispersion is explored. The micro and nano particles under study were obtained using classical methods such as the reduction in aqueous media [8,9] and the so-called polyol method [10-13]. Results show that strong reducing agent such as borohydride contaminates the products not necessarily forming borides, as has been reported previously $[8,9]$. It was found that when CTAB is used as template the system forms homogeneous microstructures distributions of secondary hollow particles with spherical morphology that organize in elongated mesoscopic systems. The powders produced were characterized by means of UV-Vis and IR spectroscopies, X-ray diffraction (XRD), Scanning and Transmission Electron Microscopies and High resolution Thermogravimetric (TG) Analyses.

\section{Experimental part}

\section{Synthesis procedures}

\section{Borohydride reduction in aqueous media}

Using a strong reducing agent, for instance $\mathrm{NaBH}_{4}$, is well documented in literature as a fast and easy method to obtain metallic nanoparticles [14]. The reduction of the starting salt $\mathrm{CoCl}_{2} \cdot 6 \mathrm{H}_{2} \mathrm{O}$ (Aldrich $\geq$ $99 \%$ ) was carried out at $25^{\circ} \mathrm{C}$ in aqueous media. First, $5 \mathrm{mmol}$ of $\mathrm{CoCl}_{2} \cdot 6 \mathrm{H}_{2} \mathrm{O}$ (Aldrich $\geq 99 \%$ ) and $5 \mathrm{mmol}$ of $\mathrm{Na}_{3} \mathrm{Cit} \cdot 2 \mathrm{H}_{2} \mathrm{O}$ (Aldrich $\geq 99 \%$ ) were dissolved into deionized water $(30 \mathrm{ml})$ under vigorous stirring. After 10 min. of stirring, $\mathrm{NaBH}_{4}$ (Aldrich $\geq 96 \%$ ) $0.0189 \mathrm{~g}$ dissolved in $20 \mathrm{ml}$ of deionized water were introduced drop by drop. The molar ratio of $\mathrm{NaBH}_{4}: \mathrm{CoCl}_{2}$ was purposely made larger than two in orders to ensure complete reduction of $\mathrm{CoCl}_{2}$ [15]. The solution color changes from pale pink into black after approximately 10 min. Eventually, the proper amount of diethyl ether $(8 \mathrm{ml})$ was then added under non-anaerobic conditions in order to minimize the formation of boron-cobalt compounds $[8,9]$.

\section{Reduction method in aqueous media via vesicles}

First, $0.0729 \mathrm{~g}$ of $\mathrm{CoCl}_{2} \cdot 6 \mathrm{H}_{2} \mathrm{O}$ were dissolved in a mixture of $25 \mathrm{ml}$ deionized water and $5 \mathrm{ml}$ methanol (Fermont 99.9\%) under constant stirring. Then $17 \mu \mathrm{l}$ of oleic acid (Aldrich 90\%) were added in order to allow the vesicles formation [16]. Immediately $\mathrm{NaOH}$ (J.T. Baker $99.7 \%$ ) is added to the solution until it reaches a $\mathrm{pH}$ value of 8 (value near the pKa of the oleic acid) [17], it will help to stabilize the vesicles. Subsequently, $0.2502 \mathrm{~g}$ of $\mathrm{Na}_{3} \mathrm{Cit} \cdot 3 \mathrm{H}_{2} \mathrm{O}$ were added to the solution and the mixture was sonicated for 15 minutes. Afterward, $0.0189 \mathrm{~g}$ of $\mathrm{NaBH}_{4}$ dissolved in $20 \mathrm{ml}$ of deionized water were introduced, drop by drop, and this mixture was then sonicated for 5 minutes. The dispersion color changes from pale milky pink into milky black.

\section{Reduction method using hydrazine (polyol pro- cess)}

$\mathrm{CoCl}_{2} \cdot 6 \mathrm{H}_{2} \mathrm{O}(0.0362 \mathrm{~g})$ and $\mathrm{CTAB}(0.05466 \mathrm{~g}$, Aldrich 99\%) were mixed and sonicated in $30 \mathrm{ml}$ of ethylene glycol (Aldrich 99.8\%) during 40 minutes. Then, the appropriate amount of monohydrated hydrazine (Aldrich 98\%) was added to the solution as soft reducing agent. The solution is then heated until the boiling point of the ethylene glycol $\left(197^{\circ} \mathrm{C}\right)$ is reached and is held at this temperature for 70 minutes. After the reaction was completed, the solution is cooled to room temperature. For comparison purposes, sodium citrate $\left(\mathrm{Na}_{3} \mathrm{Cit} \cdot 3 \mathrm{H}_{2} \mathrm{O}\right)$ was used also as capping agent instead CTAB, under same conditions described above and just changing the heating time to 140 minutes. This constitutes the fourth methodology (sample identification: $\square$ Polyol-Cit $\square$ ).

In all cases the products were separated by centrifugation and special attention was taken in washing procedure. The solid precipitate was washed with ethanol, methanol, diethyl ether and deionized water several times to thoroughly remove residual contaminations, and finally the particles were dried at ambient conditions for 9 hrs.

\section{Characterization}

UV-Vis spectra were recorded on a Jazz spectrophotometer from Ocean Optics in the wavelengths interval of 200 to $800 \mathrm{~nm}$. XRD powder patterns of the asprepared samples were obtained using Bruker D8 Advance Diffractometer and $\mathrm{CuK}_{\alpha}$ radiation, with angular step of $0.025^{\circ}$. The morphology of the as-prepared Co nanoparticles was initially characterized by an Scanning Electron Microscopy instrument SEM JEOL JEM6390 $\mathrm{LV}$ operating at an accelerating voltage interval of $15 \sim$ $20 \mathrm{kV}$ and equipped with energy dispersive X-ray spectroscopy (EDS) capabilities and a High resolution SEM (HRSEM Nova 600 NanoLab, dual beam). The samples with smaller particle sizes were analyzed by Transmission Electron Microscopy (TEM JEOL JEM 1010) and High Resolution TEM (HRTEM JEOL 2010F), using an accelerating voltage of $60 \mathrm{kV}$ and $200 \mathrm{kV}$, respectively. The thermogravimetric studies were performed 
in a High Resolution TGA Q5000 IR at heating rates of $10^{\circ} \mathrm{C} / \mathrm{min}$ under a continuous air flow $\left(21 \% \mathrm{O}_{2}\right)$. IR spectra were recorded using the $\mathrm{KBr}$ pressed disk tech- nique and Spectrum One spectrophometer (from Perkin Elemer).

Table 1 Resume of the four methodologies and the corresponding sample identification (ID)

\begin{tabular}{ccccc}
\hline Solvent & Reductor & Surfactant & Sample ID & Temperature $\left({ }^{\circ} \mathrm{C}\right)$ \\
\hline Water & $\mathrm{NaBH}_{4}$ & Sodium citrate & Aqueous reduction & Room \\
Water & $\mathrm{NaBH}_{4}$ & Oleic acid & Vesicles & Room \\
Ethylene glycol & Hydrazine & CTAB & Polyol-CTAB & 197 \\
Ethylene glycol & Hydrazine & Sodium citrate & Polyol-Cit & 197 \\
\hline
\end{tabular}

\section{Results and discussions}

The obtained colloids were first analyzed by UVVis spectra. Colloidal dispersion of metals exhibits absorption bands in the UV-Vis range as a result of intraband or interband transitions. Intraband transitions in metals due to excitation of electron plasma resonances which in the case of metallic cobalt, is expected to occur in the 120 to $162 \mathrm{~nm}$ range [18]. Due to superposition of Fermi level with empty $3 \mathrm{~s}$ bands, metallic cobalt also display interband transitions which superpose to intraband transitions. This behavior makes it difficult to analyze the electronic absorption spectra of metallic cobalt colloids as function of particle size. In all cases the UV-Vis spectra of as-prepared colloids (see Fig. 1 in online supplementary material) shows that the light scattering component along with the wavelengths range in common. This suggests that colloids mainly consist of particles or agglomerates having sizes in the order or bigger than the incident wavelengths $[19,20]$. The sample prepared from borohydride reduction in aqueous solution shows the least contribution from scattering and a progressive increase of the absorbance at smaller wavelengths. In this case the optical response suggests the presence of smaller particles/agglomerate sizes and it is in agreement with theoretical spectrum expected for metallic cobalt nanoparticles [21].

XRD pattern of the as-prepared particles obtained from borohydride reduction does not show reflections (see representative example in Fig. 1(a)) while samples obtained by reduction with hydrazine crystallizes as hcp-metallic cobalt (see Fig. 1(b)). At this point, it is important to note that borohydride is stronger reducing agent

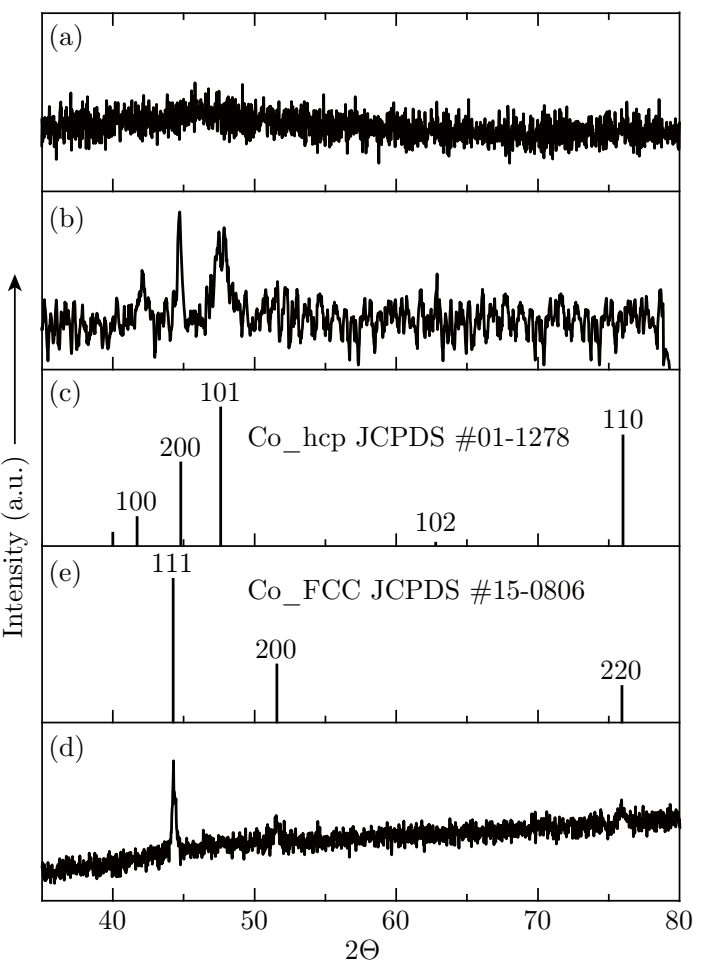

Fig. 1 Representative XRD patterns for: (a) all the asprepared Co nanoparticles from borohydride reduction; (b) using hydrazine as reducer; (d) sample showed in (a) after annealing at $500^{\circ} \mathrm{C}$; (c) and (e) Column bar plots correspond to hcp Co- JCPDS \# 01-1278 and fcc Co-JCPDS \# 15-0806, respectively.

than hydrazine; therefore the synthesis with the hydrazine needs to be carried at higher temperature which probable favors the growths of metallic cobalt nanoparticles. The samples that appear to be amorphous (aqueous reduction and vesicles), crystallize in FCC structure after an annealing at $500^{\circ} \mathrm{C}$ as shows the diffraction pattern in Fig. 1(d) (as comparison Fig. 1(e) shows expected reflections for this phase JCPDS \#15-0806). The FCC crystal structure is the stable phase for metallic cobalt at high temperature $\left(>420^{\circ} \mathrm{C}\right)$, although the ob- 
taining of FCC and e-Co metallic cobalt in solution phase at low temperature have been previously reported [22-24].

\section{TEM and SEM characterizations}

Only in two of the samples it was possible to distinguish the primary particles (i.e.: aqueous reduction and vesicles) by means of HRTEM. In the other two samples (Poly-ol-CTAB and Polyol-Cit), it is impossible to observe the detail of the samples in HRTEM due to the large size of the agglomerate. Hence these two samples were studied by SEM, which served to distinguish the secondary particle sizes, while the primary particle size was roughly estimated by the local contrast (apparent primary particle size). Figure 2 illustrates the HR-TEM micrographs of the products obtained via aqueous reduction. High Angle Annular Dark Field (HAADF) image (see Fig. 2(a)) shows roughly spherical secondary particles with mean diameters between 15 to $30 \mathrm{~nm}$; at higher resolutions the primary particles can be distinguished, having a mean diameter of $2.4 \mathrm{~nm}$. The local and global Fast Fourier Transforms of images show a unique reflection which apparently corresponds to the $\{100\}$ planes family from FCC metallic cobalt (JCPDS \# 15-0806). This is in agreement with XRD characterization of the sample (aqueous reduction, after annealing), suggesting that FCC crystal structure seems to be favored for very small particles.
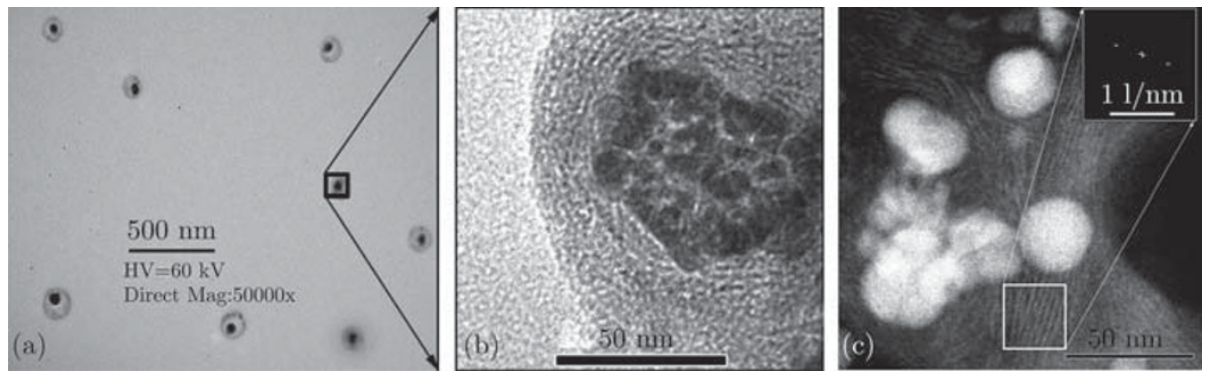

Fig. 3 (a) low resolution TEM, (b) HRTEM and (c) HAADF images of metallic cobalt obtained from vesicles. Inset in (c) corresponds to the FFT of the selected area in this image.

For the cases where ethylene glycol was used as solvent in the presence of hydrazine as reducer, the products of both methodologies (using Sodium Citrate or CTAB as stabilizers) tend to be formed by spherical micro-agglomerates of metal particles (see Fig. 4(a) and 4(c)).
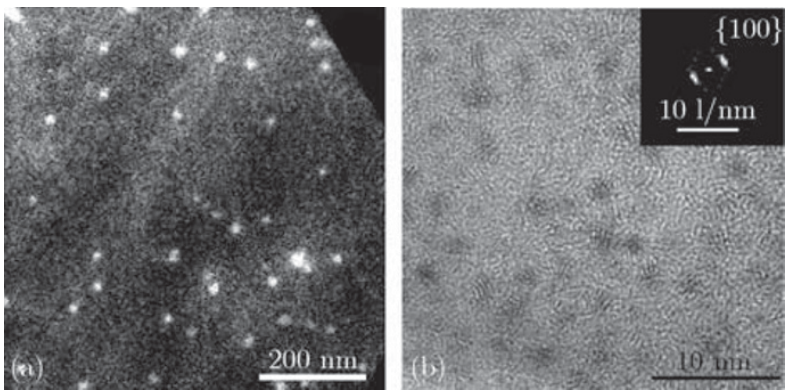

Fig. 2 (a) High Angle Annular Dark Field (HAADF) image from a zone of the obtained dispersion using sodium citrate as capping agent and sodium borohydride as reducing agent in aqueous media, (b) selected HRTEM micrograph of primary of particles. The inset in the upper part shows a FFT of selected particle showing the $\{100\}$ family plane reflection that corresponds with FCC metallic Co (JCPDS 15-0806).

On the other hand, vesicles sample which was also obtained from borohydride reduction consists in poly-disperse particles with sizes ranging from 8 to $40 \mathrm{~nm}$ encapsulated in vesicle-like globules as shown in Fig. 3(a). According to the local and global FFT of micrographs at high resolution, the particles appear to be amorphous in agreement with XRD results of the as prepared samples. In general particles seems to be coated by an organized phase having an apparent interplanar distance of $27 \AA$ (Fig. 3(b) and 3(c)), a value that is in agreement with the reported $\{100\}$ family planes of dodecanoic acid (JCPDS \# 38-1976) indicating a multilamellar organization of the oleic acid around the agglomerate of metallic particles and suggesting the formation of a vesicular system. 


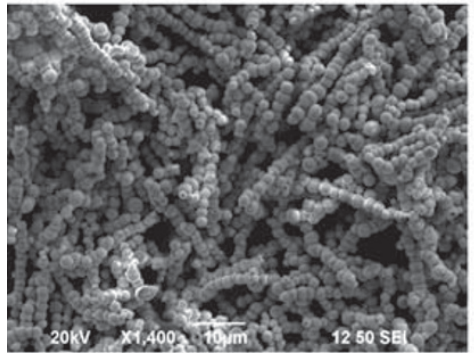

(a)

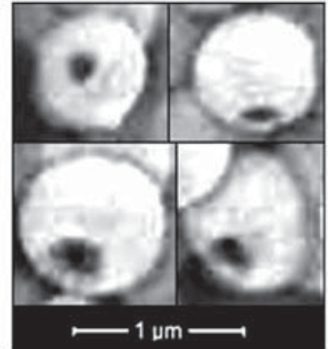

(b)

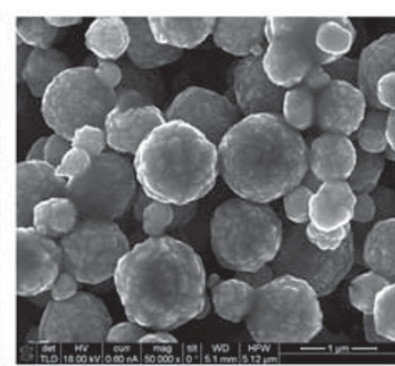

(c)

Fig. 4 (a) SEM images of sample obtained using CTAB as capping agent and hydrazine as reducing agent in ethylene glycol; (b) Zoom in on selected particles observed in SEM micrographs that shows hollow morphology; (c) sample obtained under similar conditions but using sodium citrate as capping agent.

and the use of softer reducing agent could be the reason why the mean particle sizes is higher in these cases. Both parameters probably favor the superposition of nucleation and growth processes which don't allow the obtaining of small particles. Additionally, for the sample obtained in the presence of CTAB, the agglomerates organize to form hollow-elongated mesoscopic system (see Fig. 4(b)). This is very interesting since nanoengineered colloidal particles with hollow morphology may potentially find applications as delivery systems especially those which are magnetic because they can be directed by application of an external magnetic field [25-27]. The obtaining of hollow microstructures is probably related to the formation of CTAB micelles in ethylene glycol [28]. The micelles act as template and deposition center during nucleation and the growth of metallic cobalt nanoparticles.

\section{Thermogravimetric profiles}

Pure metallic bulk cobalt starts to oxidize in air at approximately $350^{\circ} \mathrm{C}$ [29]. However, cobalt nanoparticles obtained via physical methods, with mean particle size in the range of $20 \sim 57 \mathrm{~nm}$, starts to oxidize in air at temperatures as low as $150^{\circ} \mathrm{C}$ [30,31]. In Fig. 5(a) the thermogravimetric curves of the four as prepared samples are shown and in the Table 2 the weight gain/loss for each sample and a proposal of the processes involved are summarized. Two general behaviors can be clearly distinguished depending on reducing agent used. Although all samples show a weight loss in the temperature ranges from 30 to $350^{\circ} \mathrm{C}$ (related to dehydration and decomposition of the organic phase) the less unpurified samples are those obtained from hydrazine reduction. It is almost cer- tainly that weight gain due to oxidation of metallic cobalt is partially overlapped with weight loss resulted from decomposition processes of organic phases. It is worth mentioning the fact that any attempt to measure the samples under inert atmosphere complicates the further interpretation of the thermal profiles because of residual carbonaceous material that result from incomplete combustion of the organic phase.

The unique sample showing almost no overlapping of decomposition and oxidation processes was obtained from hydrazine reduction in the presence of citrate. This sample shows the largest experimental weight gain of $31.26 \%$ and the expected theoretical value for pure metallic cobalt is $36.19 \%$ according to:

$$
3 \mathrm{Co}_{(\mathrm{s})}+2 \mathrm{O}_{2(\mathrm{~g})} \rightarrow \mathrm{Co}_{3} \mathrm{O}_{4(\mathrm{~s})}
$$

The differences between experimental and theoretical weight gain are usually assumed as result from metal surface oxidation [30]. Intriguingly, no traces of cobalt oxide were observed in XRD patterns which is probably related to low cristallinity of this compound. The existence of cobalt oxide $(\mathrm{CoO})$ in metallic cobalt samples implies that its oxidation to $\mathrm{Co}_{3} \mathrm{O}_{4}$ contributes with a fraction to the total oxygen uptake along the thermal profiles according to:

$$
3 \mathrm{CoO}_{(\mathrm{s})}+\frac{1}{2} \mathrm{O}_{2(\mathrm{~g})} \rightarrow \mathrm{Co}_{3} \mathrm{O}_{4(\mathrm{~s})}
$$

especially in the range from 400 to $900^{\circ} \mathrm{C}$ [32]. An interesting feature of the thermal profiles in samples obtained from hydrazine reduction is the existence of a well defined weight loss at $905^{\circ} \mathrm{C}$ which undoubtedly corresponds to the process 

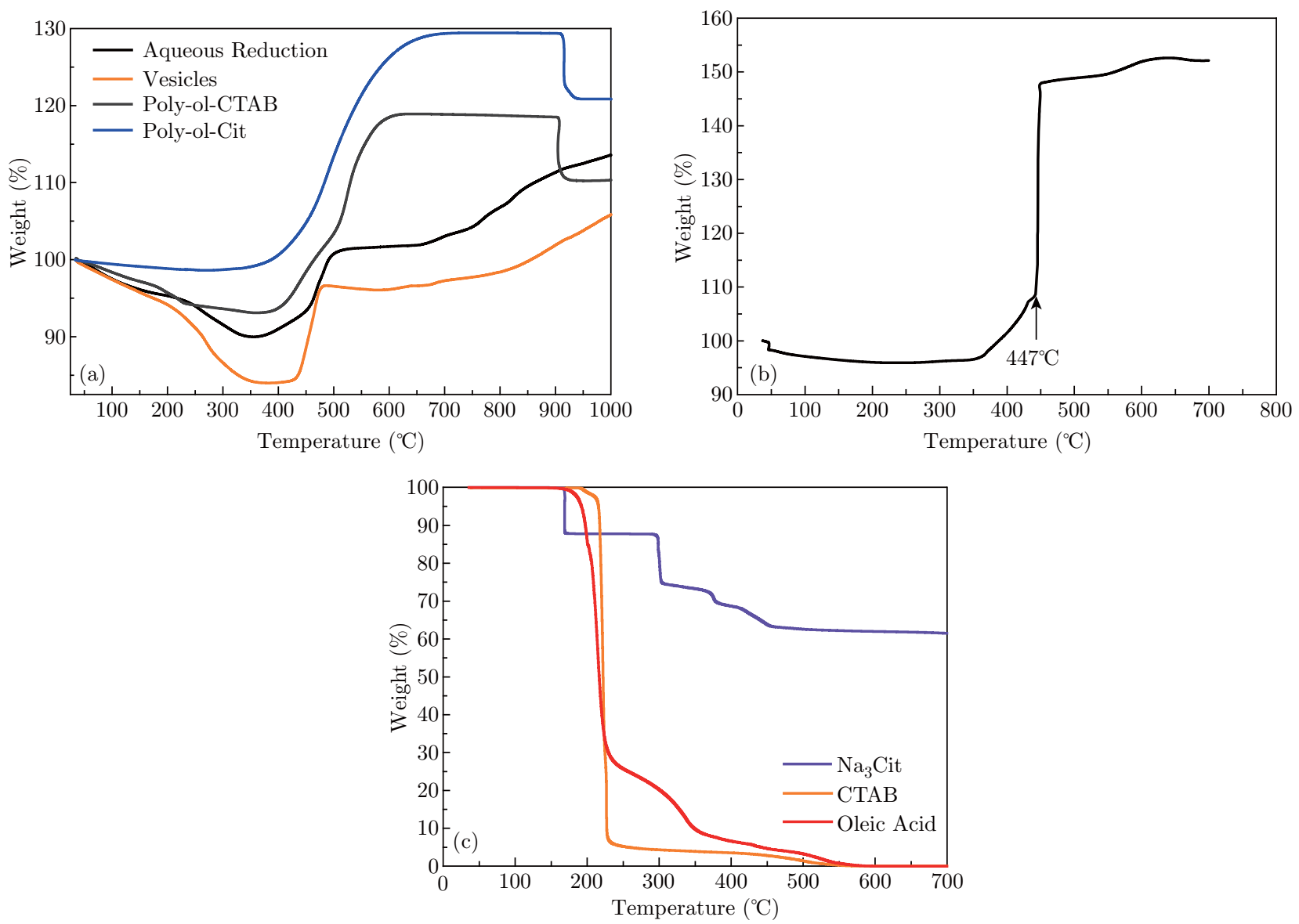

Fig. 5 (a) Thermogravimetric plots of the four as-prepared Co nanoparticles; (b) Thermogravimetric curve of the sodium borohydride; (c) Thermogravimetric curves of sodium citrate, CTAB and oleic acid (major probable impurities on samples).

Table 2 Resume of the weight gain/loss for each sample and a proposal of the processes involved

\begin{tabular}{|c|c|c|c|}
\hline Methodology & Assignment & Gain/loss(-) weight (\%) & Temperature $\left({ }^{\circ} \mathrm{C}\right)$ \\
\hline \multirow[t]{2}{*}{ Aqueous media reduction } & $\mathrm{H}_{2} \mathrm{O}$ and organic compounds lose & $-10.07 \%$ & 357 \\
\hline & $\begin{array}{c}\text { Bohydride } \\
\text { decomposition-oxidation } \\
\text { and oxidation-reaction of } \\
\text { metallic } \\
\text { phase with by-products } \\
\text { Final product: } \mathrm{Co}_{2} \mathrm{~B}_{2} \mathrm{O}_{5}\end{array}$ & $23.61 \%$ & $200 \sim 1000$ \\
\hline \multirow[t]{2}{*}{ Vesicles } & Organic compounds decomposition & $-16 \%$ & $374^{\circ}$ \\
\hline & $\begin{array}{c}\text { Bohydride } \\
\text { decomposition-oxidation } \\
\text { and oxidation-reaction of } \\
\text { metallic } \\
\text { phase with by-products } \\
\text { Final product: } \mathrm{Co}_{3}\left(\mathrm{BO}_{3}\right)_{2}\end{array}$ & $21.87 \%$ & $200 \sim 1000$ \\
\hline \multirow[t]{3}{*}{ Polyol using CTAB } & Organic compounds decomposition & $-7.06 \%$ & 360 \\
\hline & $3 \mathrm{Co}+2 \mathrm{O}_{2} \rightarrow \mathrm{Co}_{3} \mathrm{O}_{4}$ & $27.79 \%$ & $200 \sim 850$ \\
\hline & $\mathrm{Co}_{3} \mathrm{O}_{4} \rightarrow 3 \mathrm{CoO}+\frac{1}{2} \mathrm{O}_{2}$ & $-6.90 \%$ & $870 \sim 1000$ \\
\hline \multirow[t]{3}{*}{ Polyol using Citrate. } & Organic compounds decomposition & $-1.35 \%$ & 268 \\
\hline & $3 \mathrm{Co}+2 \mathrm{O}_{2} \rightarrow \mathrm{Co}_{3} \mathrm{O}_{4}$ & $31.2 \%$ & $200 \sim 850$ \\
\hline & $\mathrm{Co}_{3} \mathrm{O}_{4} \rightarrow 3 \mathrm{CoO}+\frac{1}{2} \mathrm{O}_{2}$ & $-6.636 \%$ & $870 \sim 1000$ \\
\hline
\end{tabular}


represented by [33]:

$$
2 \mathrm{Co}_{3} \mathrm{O}_{4(\mathrm{~s})} \rightarrow 6 \mathrm{CoO}_{(\mathrm{s})}+\mathrm{O}_{2(\mathrm{~g})}
$$

for this process the expected theoretical weight loss is $6.644 \%$, while experimental value is $6.636 \%$. The quantitativeness of this process allows estimating the global cobalt content by straightforward calculations taking into account the relation between reactions (1) and (3) independently of the overlapping between organic phase decomposition and oxidation processes. However, contribution to oxygen uptake from $\mathrm{CoO}$ oxidation is unknown and can be only estimated if sample is assumed to consist in a mixture of metallic cobalt and cobalt (II) oxide and both oxidize to the same product (i.e.: $\mathrm{Co}_{3} \mathrm{O}_{4}$, equation 1 and 2) without superposition of oxidation and decomposition of organic phase. For example, cobalt obtained in ethylene glycol in the presence of sodium citrate gives an approximately metallic phase content of $81.5 \%, 17.2 \%$ of cobalt oxide and $1.3 \%$ of organic phase. Obviously this is due to the fact that carbonaceous residues are not taken into account.

In samples where borohydride was used as the reducing agent, it can be observed a two step oxidation process and $\mathrm{Co}_{3} \mathrm{O}_{4}$ decomposition is not observed. By comparison with the thermogravimetric curve for pure sodium borohydride (see Fig. 5(b)) the first step appears to correspond with the oxidation of borohydride residues to borate, according to:

$$
2 \mathrm{NaBH}_{4(\mathrm{~s})}+3 / 2 \mathrm{O}_{2(\mathrm{~g})} \rightarrow \mathrm{Na}_{2} \mathrm{BO}_{3(\mathrm{~s})}+4 \mathrm{H}_{2(\mathrm{~g})}
$$

This process implies the simultaneous decomposition and oxidation of this reactant. In order to confirm the presence of borates after thermogravimetric study, XRD patterns of the samples were recorded, and the formation of $\mathrm{Co}_{3}\left(\mathrm{BO}_{3}\right)_{2}$ was corroborated for sample which was obtained in vesicular system (see Fig. 2 in online supplementary material). On the other hand, for the sample obtained via aqueous reduction in the presence of citrate, the product consists of cobalt pyroborate $\left(\mathrm{Co}_{2} \mathrm{~B}_{2} \mathrm{O}_{5}\right.$; see Fig. 3 in online supplementary material) suggesting another mechanism for reaction-oxidation of the metallic phase with borates residues. These results suggest that borate product from decomposition of borohydride residues reacts with metallic cobalt and oxygen to give cobalt borates. Other possibility that cannot be discarded is the simultaneous formation of metallic cobalt and cobalt borides composites as have been reported by Glavee et al. [8,9], in this case a two step oxidation process is also expected. Additionally, it is noted that organic phase content is higher for vesicles sample and the IR spectrum corroborates the presence of oleic acid (see Fig. 4 in online supplementary material). Bands observed at 1607 and $1498 \mathrm{~cm}^{-1}$ are characteristic of the asymmetric $\nu_{\mathrm{as}}(\mathrm{COO}-)$ and the symmetric $\nu_{\mathrm{s}}(\mathrm{COO}-)$ stretchings of oleic acid where the interaction between the $\mathrm{COO}^{-}$group and the Co atom is covalent through bridging bidentate bound [34].

\section{Conclusions}

The synthesis of metallic cobalt in aqueous media from borohydride reduction offers a convenient route to obtain metallic cobalt with smaller particle size; however, it leads to lesser purity in products than when hydrazine is used as the reducing agent. On the other hand, the synthesis achieved by the polyol process gave bigger particle sizes which agglomerate in secondary microparticles with spherical shapes. In the presence of CTAB hollow elongate mesoscopic microstructures can be obtained while in presence of sodium citrate the secondary microparticles are solid but not organized. According to thermogravimetric profiles, the system with the highest purity is obtained when hydrazine is combined with sodium citrate as surface modifier.

\section{Acknowledgements}

This work was partially supported by the Consejo Nacional de Ciencia y Tecnología (CONACYT, México) under Grant SEP-CONACyT 2009 No. 129048.

\section{References}

[1] M. N. Baibich, "Magnetism in Magnetic Materials and Their Applications", Eds, F. Leccabue and V. Sagredo, World Scientific, Singapore, pp. 69-80 (1996).

[2] M. Vopálenský, P. Ripka, J. Kubík and M Tondra, Sens. Actuators. A 110, 254 (2004). http://dx.doi. org $/ 10.1016 / j$.sna. 2003.09.036 
[3] R. P. Cowburn, Mater. Today 6, 32 (2003). http:// dx.doi .org/10.1016/S1369-7021 (03)00730-2

[4] C. Scherer and A. M. Figueiredo Neto, Braz. J. Phys. 35, 718 (2005). http://dx.doi.org/10.1590/ S0103-97332005000400018

[5] Halit S.Gokturk, Thomas J. Fiske and Dilhan M. Kalyon, J. Appl. Phys. 73, 5598 (1993). http://dx.doi. org/10.1063/1.353663

[6] G. Schmid, "Applied Homogeneous Catalysis with Organometallic Compounds", Eds, B. Cornils and W. A. Herrmann, Wiley-VCH: Weinheim, Germany, vol. 2, pp. 636-644 (1996).

[7] Yang Xu, Meena Mahmood, Zhongrui Li, Enkeleda Dervishi, Steve Trigwell, Vladimir P. Zharov, Nawab Ali, Viney Saini, Alexandru R Biris, Dan Lupu, Dorin Boldor and Alexandru S. Biris, Nanotechnology 19, 435102 (2008). http://dx.doi.org/10.1088/ 0957-4484/19/43/435102

[8] George N. Glavee, Kenneth J. Klabunde, Christopher M. Sorensen and George C. Hadjapanayis, Langmuir 8, 771 (1992). http://dx.doi.org/10.1021/ $1 \mathrm{a} 00039 \mathrm{a} 008$

[9] George N. Glavee, Kenneth J. Klabunde, Christopher M. Sorensen and George C. Hadjipanayis, Langmuir 9, 162 (1993). http://dx.doi.org/10.1021/ $1 \mathrm{a} 00025 \mathrm{a} 034$

[10] G. Viau, F. Fiévet-Vincent and F. Fiévet, Solid State Ionics 84, 259 (1996). http://dx.doi.org/10.1016/ 0167-2738 (96) 00005-7

[11] L. Poul, N. Jouini and F. Fiévet, Chem. Mater. 12, 3123 (2000). http://dx.doi.org/10.1021/cm991179j

[12] F. Fiévet, M. Figlarz and J. P. Lagier, "Process for the reduction of metallic compounds by polyols, and metallic powders obtained by this process", U. S. Patent 4539041 (1985).

[13] F. Fiévet, J. P. Lagier and B. Blin, Solid State Ionics 198, 32 (1989).

[14] L. Cushing Brian, V. L. Kolesnichenko and Charles J. O'Connor, Chem. Rev. 104, 3893 (2004).

[15] A. M. L. Jackelen, M. Jungbauer and G. N. Glavee, Langmuir 15, 2322 (1999). http://dx.doi.org/10. 1021/la9807311

[16] M. L. Rogerson, Brian H. Robinson, Seyda Bucak and Peter Walde, Colloids Surf. B 48, 24 (2006). http:// dx.doi.org/10.1016/j.colsurfb. 2006.01.001

[17] C. L. Apel, M. N. Mautner and D. W. Deamer, Biochim. Biophys. Acta. Gen. Subj. 1559, 1 (2002).

[18] L. Ward, "Handbook of Optical Constants of Solids II" Ed, Edward D. Palik, Elsevier Science, vol. 2, pp 435-448 (1991).
[19] C. F. Bohren and D. R. Huffman, "Absorption and scattering of light by small particles", Wiley, New York, (1983).

[20] H. C. Van de Hulst, "Light Scattering by Small Particles", Dover Publications, New York (1981).

[21] J. A. Creighton and D. G. Eaton, J. Chem. Soc. Faraday Trans. II 87, 3881 (1991). http://dx.doi.org/ $10.1039 /$ ft9918703881

[22] S. H. Sun and C. B. Murray, J. Appl. Phys. 85, 4325 (1999). http://dx.doi.org/10.1063/1.370357

[23] D. P. Dinega and M. G. Bawendi, Angew. Chem. Int. Ed. 38, 1788 (1999). http://dx.doi.org/10. 1002/ (SICI) 1521-3773(19990614) 38:12\$<\$1788: : AID-ANIE1788\$>\$3. 0.CO;2-2

[24] H. T. Yang, C. M. Shen, Y. G. Wang, Y. K. Su, T. Z. Yang and H. J. Gao, Nanotechnology 15, 70 (2004). http://dx.doi.org/10.1088/0957-4484/15/1/014

[25] Dobson, J. Nanomedicine (Lond) 1, 31 (2006). http://dx.doi.org/10.2217/17435889.1.1.31

[26] Manuel Arruebo, Rodrigo Fernández-Pacheco, M. Ricardo Ibarra and Jesús Santamaría, Nano Today 2, 22 (2007). http://dx.doi.org/10.1016/ S1748-0132(07)70084-1

[27] Lin Guo, Fang Liang, Xiaogang Wen, Shihe Yang, Lin He, Wangzhi Zheng, Chinping Chen and Qunpeng Zhong, Adv. Funct. Mater. 17, 425 (2007). http: //dx. doi .org/10.1002/adfm. 200600415

[28] S. K. Kor, R. R. Yadav, and D. Singh, Mol. Cryst. Liq. Cryst. 392, 75 (2002). http://dx.doi.org/10.1080/ 10587250216176

[29] A. Magdziarz, I. Suliga and Z. Kalicka, J. Therm. Anal. Calorim. 74, 647 (2003). http://dx.doi.org/ 10.1023/B: JTAN. $0000005206.63933 .2 \mathrm{f}$

[30] Robert N. Grass and Wendelin J. Stark, J. Mater. Chem. 16, 1825 (2006). http://dx.doi.org/10.1039/ b601013j

[31] Hari Bala, Wuyou Fu, Yanhui Yu, Haibin Yang and Yishun Zhang, Appl. Surf. Sci. 255, 4050 (2009). http://dx.doi.org/10.1016/j. apsusc. 2008.10. 119

[32] Chih-Wei Tang, Chen-BinWang and Shu-Hua Chien, Thermochim. Acta. 473, 68 (2008).

[33] Barbara Prochowska-Klisch and Andrzej Malecki, Thermochim. Acta. 335, 99 (1999). http://dx.doi. org/10.1016/S0040-6031 (99)00154-9

[34] Nianqiang Wu, Lei Fu, Ming Su, Mohammed Aslam, Ka Chun Wong and Vinayak P. Dravid, Nano Lett. 4, 383 (2004). http://dx.doi.org/10.1021/n1035139x 